14

\title{
Незаполненные электронные состояния ультратонких пленок кватерфенила на поверхностях послойно сформированного CdS и окисленного кремния
}

\author{
(C) А.С. Комолов ${ }^{1}$, Э.Ф. Лазнева ${ }^{1}$, Н.Б. Герасимова ${ }^{1}$, В.С. Соболев ${ }^{1}$, Е.В. Жижин ${ }^{1}$, \\ C.А. Пшеничнюк ${ }^{2}$, Н.Л. Асфондиаров ${ }^{2}$, B. Handke $^{3}$ \\ ${ }^{1}$ Санкт-Петербургский государственный университет, \\ Санкт-Петербург, Россия \\ ${ }^{2}$ Институт физики молекул и кристаллов Уфимского федерального исследовательского центра РАН, \\ Уфа, Россия \\ ${ }^{3}$ AGH University of Science and Technology, Faculty of Material Science and Ceramics, \\ 30-059 Kraków, Poland \\ E-mail: a.komolov@spbu.ru
}

Поступила в Редакцию 1 апреля 2021 г.

В окончательной редакции 3 апреля 2021 г.

Принята к публикации 3 апреля 2021 г.

Приведены результаты исследования незаполненных электронных состояний и формирования пограничного потенциального барьера при термическом вакуумном осаждении ультратонких пленок кремния 4-кватерфенила на поверхности $\mathrm{CdS}$ и на поверхности окисленного кремния. Методом рентгеновской фотоэлектронной спектроскопии (XPS) установлено, что атомные концентрации Сd и S являлись одинаковыми в составе поверхности слоя $\mathrm{CdS}$ толщиной $75 \mathrm{~nm}$, сформированного методом молекулярного наслаивания (ALD - atomic layer deposition). Исследования электронных характеристик пленок 4-кватерфенила, толщиной до $8 \mathrm{~nm}$, проводили в процессе их осаждения на поверхность сформированного слоя CdS и на поверхность окисленного кремния методом спектроскопии полного тока (TCS) в энергетическом диапазоне от 5 до $20 \mathrm{eV}$ выше $E_{\mathrm{F}}$. Установлено энергетическое расположение основных максимумов тонкой структуры спектров полного тока (ТССПТ) пленок 4-кватерфенила. Расположение максимумов воспроизводимо при использовании двух выбранных материалов подложек. Установлено незначительное снижение работы выхода, от 4.2 до $4.1 \mathrm{eV}$, в процессе термического осаждения 4-кватерфенила на поверхность CdS. При осаждении пленки 4-кватерфенила на поверхность окисленного обнаружено повышение значений работы выхода от 4.2 до $4.5 \mathrm{eV}$. Обсуждаются возможные механизмы физико-химического взаимодействия между пленкой 4-кватерфенила и поверхностью исследованных подложек, приводящие к различию наблюдаемых значений работы выхода пленок на этих подложках.

Ключевые слова: олигомеры фенилена, 4-кватерфенил, ультратонкие пленки, CdS--метод молекулярного наслаивания (ALD - atomic layer deposition), электронные свойства, низкоэнергетическая электронная спектроскопия, рентгеновская фотоэлектронная спектроскопия (XPS).

DOI: 10.21883/FTT.2021.08.51175.071

\section{1. Введение}

Тонкие пленки олигофениленов, а также соолигомеров фенилена и тиофена представляют интерес в качестве материалов для разработки органических диодных и транзисторных устройств [1-3]. При определенных условиях синтеза удается сформировать монокристаллические фрагменты таких олигомеров [4]. Значения подвижности носителей заряда в макетах органических полевых транзисторов (OFET) соолигомеров тиофена и финилена достигали порядка $10^{-1} \mathrm{~cm}^{2} /(\mathrm{V} \cdot \mathrm{s})$ [5]. Увеличения подвижности носителей заряда примерно на порядок можно ожидать при использовании гибридных органических/неорганических слоев в составе OFET [6,7]. В качестве модельного ультратонкого гибридного слоя может выступать и пограничная область, сформированная пленкой олигомера и поверхностью твердотельной подложки. Среди олигомеров фенилена в качестве достаточно простой модельной молекулы интерес представляет 4-кватерфенил (4-quaterphenyl, $4 Q$ ), называемый также пара-кватерфенилом ( $p$-quaterphenyl) (рис. 1). Тонкие и ультратонкие слои $4 Q$ на поверхности твердотельных подложек продемонстрировали полупроводниковые свойства $[8,9]$ и возможность использования в качестве электронных устройств на основе отдельных молекул [10]. Согласно результатам работы [8], значения оптической ширины запрещенной зоны термически осажденных в вакууме пленок $4 Q$ составляли $2.3-2.4 \mathrm{eV}$. Значительный интерес исследователей привлекают материалы подложек на основе двумерных (2D) неорганических полупроводников, например, $\mathrm{CdS}$ и $\mathrm{ZnO}$, сформированных методом ALD [11-13]. При формировании CdS-методом ALD используют Cd-содержащие и серосодержащие 


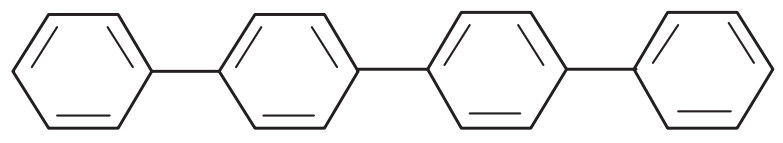

Рис. 1. Структурная формула молекулы 4-кватерфенила $(4 Q)$.

реагенты. При температурах $150-200^{\circ} \mathrm{C}$ потоки паров этих реагентов поочередно направляют на кремниевую подложку. Показано, что так могут быть сформированы сплошные CdS-слои толщиной от нескольких $\mathrm{nm}$ до нескольких сотен $\mathrm{nm}$. Приготовленные

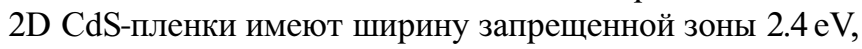
т. е. значения, характерные для этого полупроводникового материала.

Ранее нами были исследованы электронные состояния зоны проводимости пленок, термически осажденных в вакууме, на основе соолигомеров фенилена и тиофена [14] и пленок $4 Q$ на кремниевой подложке [15]. Эксперименты по исследованию электронных состояний органических материалов и по исследованию формирования потенциального барьера между органическим материалом и подложкой проводили с использованием метода спектроскопии полного тока (TCS - Total Current Spectroscopy) [16,17]. Для нескольких видов сопряженных органических материалов было показано, что TCS-результаты по установлению структуры максимумов плотности незаполненных электронных состояний плотности (DOUS) хорошо соответствуют результатам полученным другими электронно-спектроскопическими методами, такими как спектроскопия электронного захвата (electron attachment spectroscopy) [18,19], и результатам теоретических расчетов на основе теории функционала плотности $[14,15]$. В настоящей работе приведены результаты исследований методом TCS незаполненных электронных состояний ультратонких пленок $4 Q$ на поверхности $\mathrm{CdS}$, сформированного методом ALD. Приводится сравнение с TCS-результатами исследований пленок $4 Q$ на поверхности окисленного кремния. Особое внимание уделено установлению атомного состава подложки $\mathrm{CdS}$, сформированной в ходе работы.

\section{2. Эксперимент}

В качестве подложек для нанесения пленок использовали поверхности $\left(\mathrm{SiO}_{2}\right) n-\mathrm{Si}$, и поверхность бинарного полупроводника $\mathrm{CdS}$, приготовленную методом ALD. Для синтеза $\mathrm{CdS}$ использовали реагенты диметил-Cd и $\mathrm{H}_{2} \mathrm{~S}$, в атмосфере которых поочередно экспонировали поверхность кремниевой подложки, как описано в работах $[11,20]$. Производили поочередное нанесение слоев атомов $\mathrm{Cd}$ и $\mathrm{S}$. Температуру во время синтеза поддерживали $200^{\circ} \mathrm{C}$. В настоящей работе использовали слои $\mathrm{CdS}$ толщиной $75 \mathrm{~nm} \mathrm{c} \mathrm{шероховатостью} \mathrm{не} \mathrm{более} 5 \mathrm{~nm}$. Поверх- ность $\left(\mathrm{SiO}_{2}\right) n-\mathrm{Si}$, предварительно очищали в $10 \%$ растворе HF. В результате такой процедуры очистки на поверхности кремния формируется слой оксида кремния толщиной $3-5 \mathrm{~nm}$, и из воздуха адсорбируются кислород- и углеродсодержащие примеси [14,21-24]. Поэтому непосредственно перед измерениями проводили очистку поверхностей подложек методом ионной бомбардировки, пучком ионов $\mathrm{Ar}^{+}$. Изучение атомного состава сформированного CdS-слоя проводили методом рентгеновской фотоэлектронной спектроскопии (XPS) на фотоэлектронном спектрометре Escalab 250Xi (Thermo Fisher Scientific Inc.) с энергией падающих фотонов $\mathrm{Al} K_{\alpha}=1486.6 \mathrm{eV}$. Исследования проводили в условиях сверхвысокого вакуума порядка $10^{-7} \mathrm{~Pa}$ при комнатной температуре. При анализе измеренных XPS-спектров использовали библиотеку стандартных XPS-спектров производителя оборудования, учитывали атомные факторы чувствительности регистрации сигнала [25].

Для формирования органических пленок использовали реактив 4-кватерфенил $(4 Q)$, приобретенный в Acros Organics (рис. 1). Кювета с реактивом была обезгажена путем выдерживания в вакууме при базовом давлении $10^{-6} \mathrm{~Pa}$ при температуре $100^{\circ} \mathrm{C}$ в течение $2-3 \mathrm{~h}$ очищены в течение нескольких часов путем прогрева при $100^{\circ} \mathrm{C}$ в высоком вакууме. Термическое осаждение $4 Q$-пленок этих проводили при скорости $0.1 \mathrm{~nm} / \mathrm{min}$. Расстояние от кюветы с реактивом до подложки составляло $10 \mathrm{~cm}$. Толщину осажденного слоя контролировали с помощью кварцевого резонатора. В процессе осаждения пленок допускали повышение давления в вакуумной камере на порядок от базового давления.

Измерения электронных характеристик серии последовательно нанесенных пленок $4 Q$ проводили методом спектроскопии полного тока (TCS), которую обсуждали подробно в работах $[14,26]$. Энергию электронов в тестирующем пучке варьировали в диапазоне от 0 до $25 \mathrm{eV}$ относительно уровня вакуума $\left(E_{\mathrm{vac}}\right)$ исследованной поверхности. При превышении энергии пучка значения $E_{\text {vac }}$ формируется тонкая структура спектров полного тока (ТССПТ). Расположение максимумов ТССПТ несет информацию о расположении особенностей функции плотности незаполненных электронных состояний (DOUS - Density of Unoccupied Electronic States) исследованного материала $[14,27]$. При увеличении толщины $4 Q$-покрытия до 8-10 nm ТССПТ, исходящая от подложки, затухала, и формировалась новая ТССПТ-структура максимумов, исходящая от осажденного органического слоя. Калибровку энергетической шкалы относительно уровня Ферми системы $\left(E_{\mathrm{F}}\right)$ проводили с использованием поверхности высокоупорядоченного пиролитического графита (HOPG - Highly Oriented Pyrolytic Graphite). Поверхность HOPG демонстрирует хорошо воспроизводимые значения электронной работы выхода около $4.6 \mathrm{eV}$ [28]. 


\section{3. Результаты и обсуждение}

Выращенные послойно при использовании метода ALD-покрытия CdS обладают хорошо воспроизводимыми свойствам [11,12]. Однако выбор температурного режима и других характеристик ALD-процесса может в некоторой степени влиять на структурные и электронные свойства приготовленных полупроводников. Для уточнения атомного состава сформированных слоев $\mathrm{CdS}$ были проведены исследования методом XPS. B XPSспектрах образцов, помещенных в аналитическую вакуумную камеру после нахождения на воздухе, обнаружены отчетливые максимумы, соответствующие атомам $\mathrm{CdS}$, а также атомов адсорбированных примесей $\mathrm{O}$ и С. Относительная концентрация примесных атомов С в 2-3 раза превышала концентрацию атомов О, поэтому для анализа выбрали XPS-максимумы остовных уровней $\mathrm{C}_{1 s}, \mathrm{Cd}_{3 d}$ и $\mathrm{S}_{2 p}$ (рис. 2). С учетом факторов XPS-чувствительности [25] были установлены относительные концентрации атомных компонент исследованной поверхности. Так, до проведения предварительной обработки ионами $\mathrm{Ar}^{+}$относительная концентрация атомов С составила примерно $30 \%$, содержание атомов $\mathrm{Cd}$ и $\mathrm{S}$ было примерно одинаковым и составило примерно $30 \%$, содержание атомов О составило 10\%. Известно, что ввиду адсорбции примесей из воздуха содержание углерода и кислорода на поверхности полупроводников может превышать 25-30\% [29,30]. Для очистки адсорбатов с исследованной поверхности использовали обработку ионами $\mathrm{Ar}^{+}$с энергией $3 \mathrm{keV}$ в течение $10 \mathrm{~s}$. В результате очистки относительная концентрация атомов С снизилась менее $10 \%$, а содержание атомов $\mathrm{Cd}$ и $\mathrm{S}$ достигло 40-45\%. Соответствующее изменение интенсивностей максимумов остовных уровней $\mathrm{C}_{1 s}, \mathrm{Cd}_{3 d}$ и $\mathrm{S}_{2 p}$ в результате проведенной очистки поверхности видно из рис. 2 при сравнении XPS-спектров, измеренных до и после $\mathrm{Ar}^{+}$очистки. Отметим, что форма максимумов $\mathrm{Cd}_{3 d}$ и $\mathrm{S}_{2 p}$ в результате очистки практически не изменилась (рис. 2, $c, d, e, f$ ). При этом и соотношение относительных концентраций атомов $\mathrm{Cd}$ и $\mathrm{S}$ осталось неизменным и составило $1: 1$. Такой атомный состав слоя $\mathrm{CdS}$, приготовленного методом ALD, отличается от состава монокристаллического $\mathrm{CdS}$, исследованного нами ранее. Так, при исследовании монокристаллической поверхности $\mathrm{CdS}(000 \overline{1})$ соотношение концентраций атомов $\mathrm{Cd}$ и $\mathrm{S}$ составляло $1: 1.5$ [31,32].

Экспериментально измеренная тонкая структура спектров полного тока (ТССПТ) обусловлена изменением вероятности входа падающих электронов в исследуемую поверхность в зависимости от энергии электронов в тестирующем пучке. Энергетический диапазон для регистрации ТССПТ расположен обычно в пределах от 5 до $25 \mathrm{eV}$ выше $E_{\mathrm{F}}$. Серия ТССПТ, измеренная в процессе осаждения пленок $4 Q$ на поверхность ALD $\mathrm{CdS}$, представлена на рис. 3. При толщине органического покрытия $0 \mathrm{~nm}$ ТССПТ соответствует поверхности подложки $\mathrm{CdS}$ без органического покрытия. В этой ТССПТ
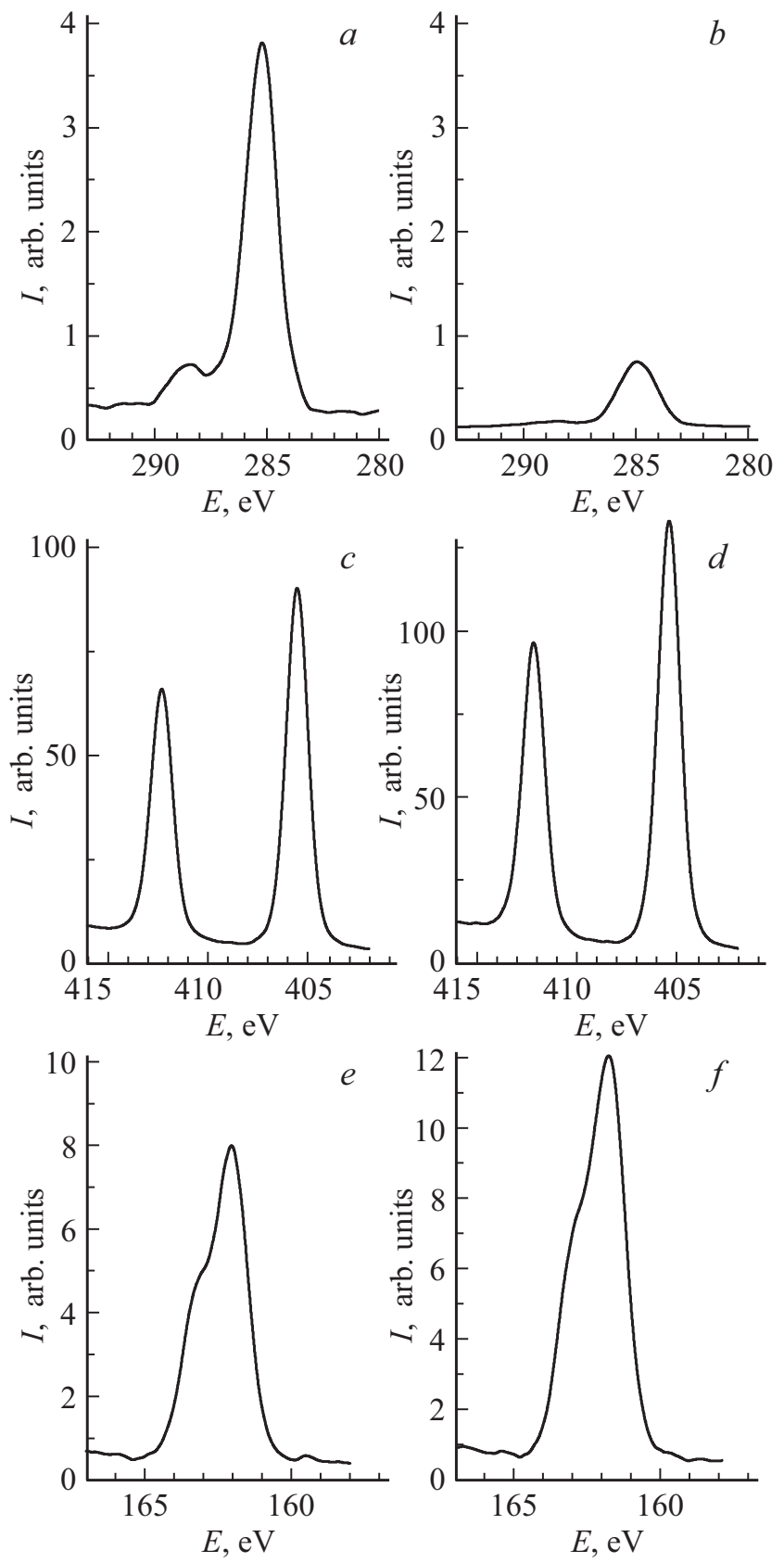

Рис. 2. Рентгеновские фотоэлектронные (XPS) спектры поверхности $\mathrm{CdS}$ подложки, сформированной методом ALD, в области максимума остовного уровня $\mathrm{C} 1 \mathrm{~s}$ без предварительной обработки $(a)$ и после обработки ионами $\operatorname{Ar}^{+}(b)$, в области максимума остовного уровня $\mathrm{Cd}_{3 d}$ без предварительной обработки $(c)$ и после обработки ионами $\mathrm{Ar}^{+}(d)$, в области максимума остовного уровня $\mathrm{S}_{2 p}$ без предварительной обработки $(e)$ и после обработки ионами $\mathrm{Ar}^{+}(f)$. Обработку исследованных поверхностей проводили ионами $\mathrm{Ar}^{+}$с энергией $3 \mathrm{keV}$ в течение $10 \mathrm{~s}$.

наблюдаются отчетливые максимумы при энергиях 7.0, 9.5 и $12.5 \mathrm{eV}$ (рис. 3). Расположение двух низкоэнергетических максимумов соответствуют расположению максимумов ТССПТ от кристаллической поверхности 


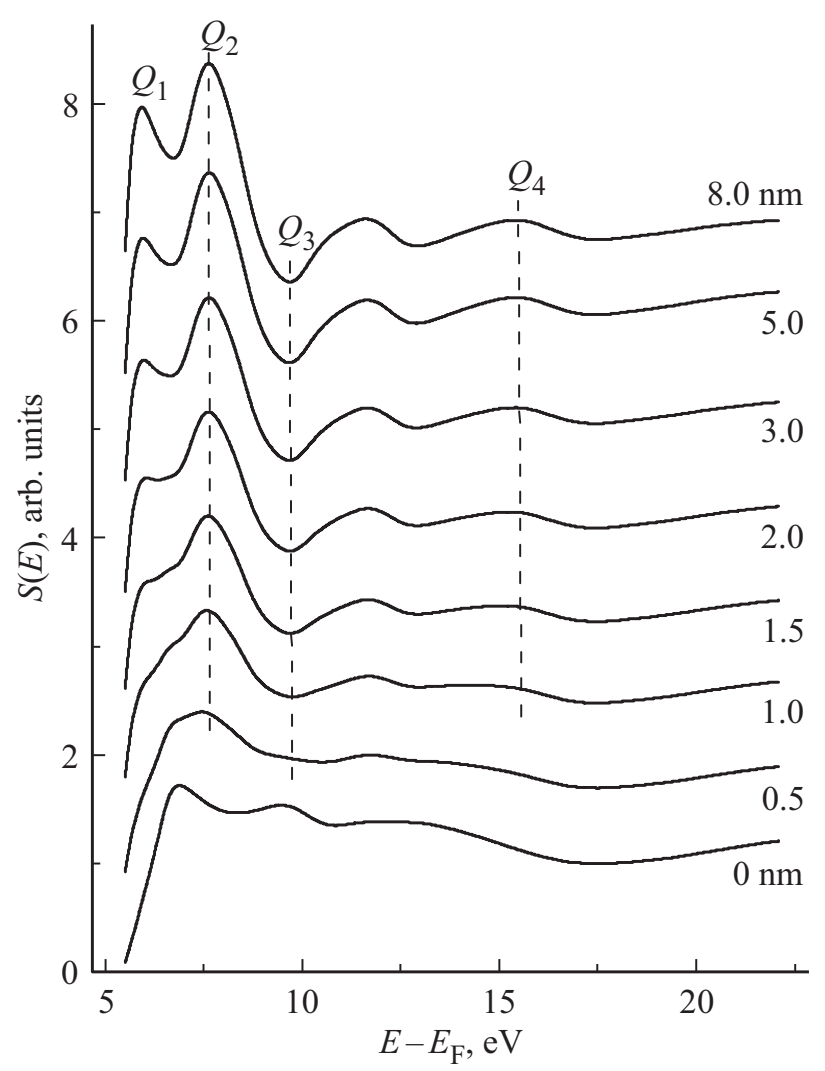

Рис. 3. Серия ТССПТ в процессе осаждения пленок $4 Q$ на поверхность CdS, сформированную методом ALD. Подписи около кривых указывают соответствующую толщину органического покрытия от 0 до $8 \mathrm{~nm}$. Наиболее отчетливые максимумы ТССПТ-пленок $4 Q$ обозначены $Q_{1}-Q_{4}$. Вертикальные штриховые пунктирные линии показаны для удобства сравнения положений максимумов.

$\mathrm{CdS}$ [31]. В процессе осаждения органического покрытия $4 Q$ толщиной до $8 \mathrm{~nm}$ ТССПТ подложки затухала, и одновременно нарастала интенсивность новых максимумов ТССПТ $Q_{1}-Q_{4}$ (рис. 3). Эти максимумы расположены при энергиях 6.0, 7.5, 11.5 и $15.5 \mathrm{eV}$, что хорошо соответствует расположению максимумов ТССПТ-пленок $4 Q$ на поверхностях поликристаллического золота и окисленного кремния, исследованных нами ранее [15]. При этом в области энергий выше $18 \mathrm{eV}$ в ТССПТ на рис. 3 максимумов не обнаружено, а в работе [15] удалось зарегистрировать максимум $Q_{5}$ при $20 \mathrm{eV}$, исходящий от пленки $4 Q$. Вероятно, выбор материала подложки или отклонения в условиях термического осаждения пленок могут приводить к размытию слабовыраженных особенностей ТССПТ. Вместе с этим для разных видов сопряженных органических пленок мы показали, что энергетическое положение наиболее отчетливых максимумов ТССПТ не зависит от выбора материала подложки при толщине органического покрытия более $5 \mathrm{~nm}[14,17,30,31]$. С целью установления возможного влияния подложки был произведено измерение серии ТССПТ в процессе осаждения пленок $4 Q$ на поверхность подложки $\left(\mathrm{SiO}_{2}\right) n-\mathrm{Si}$ (рис. 4). ТССПТ $\left(\mathrm{SiO}_{2}\right) n-\mathrm{Si}$ подложки (рис. 4) при нулевой толщине органического покрытия явно отличается от ТCCПТ CdS подложки (рис. 3). В процессе осаждения пленки $4 Q$ уже при толщине органического покрытия более $1 \mathrm{~nm}$ начинают формироваться максимумы $Q_{1}-Q_{4}$, характерные для пленки $4 Q$. При толщине пленки более $5 \mathrm{~nm}$ ТССПТ исследованной поверхности совпадает для случаев выбранных подложек $\left(\mathrm{SiO}_{2}\right) n-\mathrm{Si}$ и $\mathrm{CdS}$, приготовленной методом ALD (рис. 3 и 4). Установление $\pi^{*}$ или $\sigma^{*}$ характера наблюдаемых максимумов $Q_{1}-Q_{4}$ ТССПТ пленок $4 Q$ целесообразно провести с учетом известных из литературы результатов теоретических расчетов и результатов исследований методом ультрафиолетовой фотоэлектронной спектроскопии $[9,15]$. Так, два максимума ТССПТ $Q_{1}$ и $Q_{2}$, расположенные в энергетическом диапазоне от 5 до $10 \mathrm{eV}$ выше $E_{\mathrm{F}}$ (рис. 3 и 4), следует связать с границами зон $p^{*}$ электронных состояний. Максимумы ТССПТ $Q_{3}$ и $Q_{4}$ при энергиях 11.5 и $15.5 \mathrm{eV}$, вероятнее всего, соответствуют границами энергетических зон $\sigma^{*}$ электронных состояний.

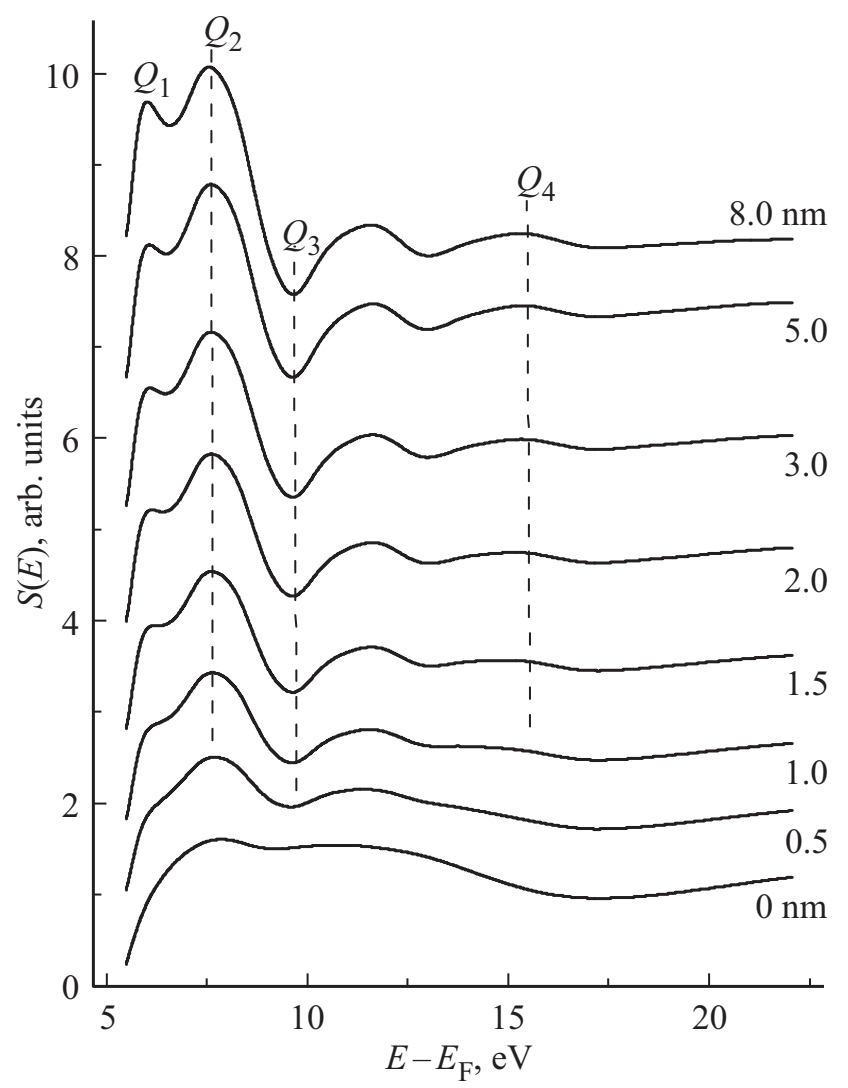

Рис. 4. Серия ТССПТ в процессе осаждения пленок $4 Q$ на поверхность $\left(\mathrm{SiO}_{2}\right) n$ - $\mathrm{Si}$. Подписи около кривых указывают соответствующую толщину органического покрытия от 0 до $8 \mathrm{~nm}$. Максимумы ТССПТ пленок $4 Q Q_{1}-Q_{4}$ расположены при тех же значениях энергии, что и в случае CdS-подложки. Вертикальные штриховые линии показаны для удобства сравнения положений максимумов. 

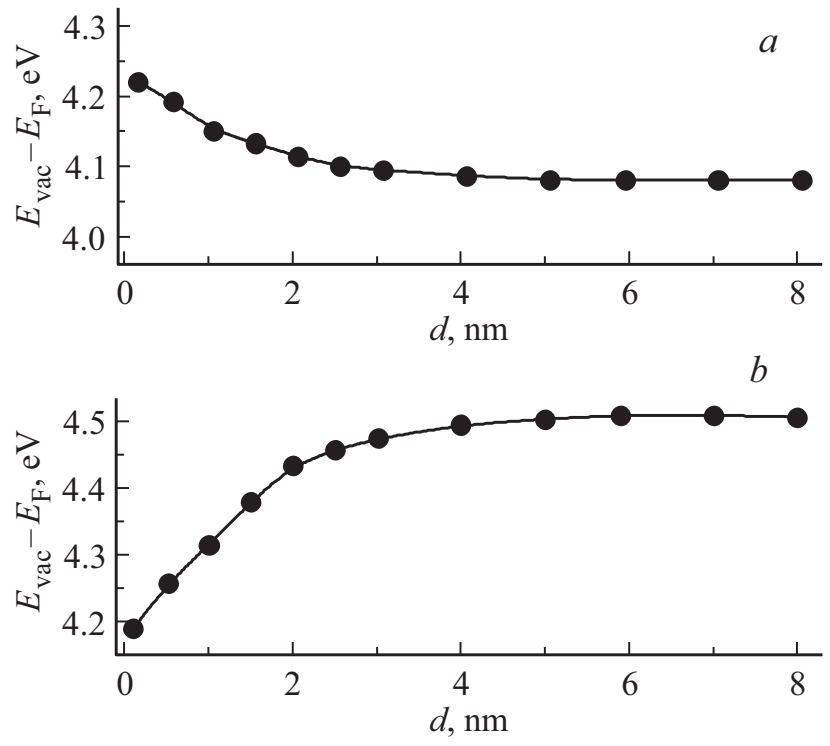

Рис. 5. Изменение положения уровня вакуума $E_{\text {vac }}$ относительно $E_{\mathrm{F}}$ в зависимости от толщины осажденного слоя $4 Q$ на подложку $(a) \mathrm{CdS}$ и $(b)\left(\mathrm{SiO}_{2}\right) n$-Si на основе результатов TCS-измерений.

Анализ формирования потенциального барьера в процессе осаждения пленки $4 Q$ на поверхности исследованных подложек производили путем измерения энергетического положения первичного TCS-максимума. C учетом результатов калибровки энергетической шкалы TCSинструмента были установлены изменения значения $E_{\text {vac }}$ исследованной поверхности относительно $E_{\mathrm{F}}$ при осаждении пленки $4 Q$ на обе исследованные подложки (рис. 5). Погрешность определения значений $E_{\mathrm{vac}}-E_{\mathrm{F}}$ coставляет $0.1 \mathrm{eV}$ вследствие разброса энергий электронов в тестирующем пучке. Значения работы выхода обеих поверхностей $\mathrm{CdS}$ и $\left(\mathrm{SiO}_{2}\right) n-\mathrm{Si}$ оказались одинаковыми $4.2 \pm 0.1 \mathrm{eV}$, что является совпадением, по мнению авторов. Действительно, для кристаллической поверхности CdS ранее было установлено значение работы выхода $4.4 \mathrm{eV}$ [31]. В случае CdS-слоя, приготовленного методом ALD, значение работы выхода может несколько отличаться. Отметим, что обнаружено отличие и в отношении концентраций атомов $\mathrm{Cd}$ и $\mathrm{S}$, согласно результатам XPS-исследований. Значение $E_{\mathrm{vac}}-E_{\mathrm{F}} 4.2 \pm 0.1 \mathrm{eV}$ является характерным для поверхности $\left(\mathrm{SiO}_{2}\right) n-\mathrm{Si}$ с учетом проведенной предварительной очистки [16,33]. Несколько меньшие значения работы выхода этой поверхности, $4.0 \pm 0.1 \mathrm{eV}$, были зарегистрированы нами ранее [15]. Это различие, скорее всего, обусловлено отклонениями в процедуре предварительной очистки.

В результате осаждения пленки $4 Q$ на поверхность $\mathrm{CdS}$ обнаружено незначительное снижение работы выхода, на $0.1 \mathrm{eV}$ (рис. 5, $a$ ). При осаждении пленки $4 Q$ на поверхность $\left(\mathrm{SiO}_{2}\right) n$-Si обнаружено повышение значений $E_{\mathrm{vac}}-E_{\mathrm{F}}$ до $4.5 \pm 0.1 \mathrm{eV}$ (рис. $5, b$ ). Повышение значений
$E_{\mathrm{vac}}-E_{\mathrm{F}}$ соответствует переносу электронного заряда из $\left(\mathrm{SiO}_{2}\right) n-\mathrm{Si}$ подложки в $4 Q$-пленку, что наблюдалось нами и другими авторами ранее в пограничной области пленок олигомеров фенилена [15,34]. Отметим, что экспериментально установленные значения работы выхода пленок $4 Q$ различаются в случае формирования пленки на $\mathrm{CdS}$ и на $\left(\mathrm{SiO}_{2}\right) n-\mathrm{Si}$-положке. Согласно литературным данным, при отсутствии взаимодействия на границе подложка/органическая пленка значение работы выхода не зависит от выбора подложки [35,36]. Часто значение работы выхода приходит к насыщению в достаточно узком слое органического покрытия, толщиной $1-3 \mathrm{~nm}$. Авторы предполагают, что наблюдаемые различающиеся между собой значения работы выхода пленок $4 Q$ обусловлены формированием поляризационного слоя на границе пленки и подложки [36-38], диффузией молекул из газовой фазы или диффузией атомов подложки в органическую пленку $[28,30]$.

\section{4. Выводы}

Методом термического вакуумного осаждения сформированы пленки олигофенилена 4-кватерфенила на поверхности $\mathrm{CdS}$, сформированной методом ALD, и на поверхности окисленного кремния. XPS-анализ показал, что соотношение атомных концентраций $\mathrm{Cd}$ и $\mathrm{S}$ в составе приготовленного слоя $\mathrm{CdS}$ толщиной $75 \mathrm{~nm}$ составило $1: 1$. Путем измерений методом TCS в процесce формирования покрытия 4-кватерфенила толщиной до $8 \mathrm{~nm}$ установлено формирование структуры максимумов незаполненных электронных состояний. Максимумы расположены в энергетическом диапазоне от 5 до $20 \mathrm{eV}$ выше $E_{\mathrm{F}}$, их расположение воспроизводимо при использовании двух выбранных материалов подложки. Установлено незначительное снижение работы выхода, от 4.2 до $4.1 \mathrm{eV}$, в процессе термического осаждения 4-кватерфенила на поверхность $\mathrm{CdS}$. При осаждении пленки 4-кватерфенила на поверхность окисленного кремния обнаружено повышение значений работы выхода от 4.2 до $4.5 \mathrm{eV}$. Повышение значений работы выхода соответствует переносу электронного заряда из Si подложки в пленку 4-кватерфенила.

\section{Финансирование работы}

TCS-исследования пленок 4-кватерфенила на кремнии выполнены при поддержке гранта Российского научного фонда № 19-13-00021. Исследования поверхности сформированного CdS выполнены при поддержке гранта РФФИ (20-03-00026). В работе использовали оборудование Научного парка СПбГУ „Физические методы исследования поверхности“, „Инновационные технологии композитных наноматериалов“.

\section{Конфликт интересов}

Авторы заявляют, что у них нет конфликта интересов. 


\section{Список литературы}

[1] A.A. Attia, M.M. Saadeldin, H.S. Soliman, A.-S. Gadallah, K. Sawaby. Opt. Mater. 62, 711 (2016).

[2] M.S. Kazantsev, V.G. Konstantinov, D.I. Dominskiy, V.V. Bruevich, V.A. Postnikov, Y.N. Luponosov, V.A. Tafeenko, N.M. Surin, S.A. Ponomarenko, D.Y. Paraschuk. Synt. Met. 232, 60 (2017).

[3] В.А. Постников, М.С. Лясникова, А.А. Кулишов, В.В. Гребенев, О.В. Борщев. ЖФХ 93, 1362 (2019).

[4] V.A. Postnikov, Y.I. Odarchenko, A.V. Iovlev, V.V. Bruevich, A.Y. Pereverzev, L.G. Kudryashova, V.V. Sobornov, L. Vidal, D. Chernyshov, Y.N. Luponosov, O.V. Borshchev, N.M. Surin, S.A. Ponomarenko, D.A. Ivanov, D.Y. Paraschuk. Cryst. Growth Des. 14, 1726 (2014).

[5] L.G. Kudryashova, M.S. Kazantsev, V.A. Postnikov, V.V. Bruevich, Y.N. Luponosov, N.M. Surin, O.V. Borshchev, S.A. Ponomarenko, M.S. Pshenichnikov, D.Y. Paraschuk. ACS Appl. Mater. Interfaces 8, 10088 (2016).

[6] А.Н. Алешин, И.П. Щербаков, Д.А. Кириленко, Л.Б. Матюшкин, В.А. Мошников. ФТТ 61, 388 (2019).

[7] П.С. Крылов, А.С. Берестенников, С.А. Фефелов, А.С. Комолов, А.Н. Алешин. ФТТ 58, 2476 (2016).

[8] A.A.A. Darwish. Infrared Phys. Technology 82, 96 (2017).

[9] P.G. Schroeder, M.W. Nelson, B.A. Parkinson, R. Schlaf. Surf. Sci. 459, 349 (2000).

[10] P. Shen, M. Huang, J. Qian, J. Li, S. Ding, X.-S. Zhou, B. Xu, Z. Zhao, B.Z. Tang. Angew. Chem. Int. Ed. 59, 4581 (2020).

[11] J.R. Bakke, H.J. Jung, J.T. Tanskanen, R. Sinclair, S.F. Bent. Chem. Mater. 22, 4669 (2010).

[12] N.P. Dasgupta, X. Meng, J.W. Elam, A.B.F. Martinson. Acc. Chem. Res. 48, 341 (2015).

[13] H. Frankenstein, C.Z. Leng, M.D. Losego, G.L. Frey. Organic Electron. 64, 37 (2019).

[14] A.S. Komolov, E.F. Lazneva, N.B. Gerasimova, Yu.A. Panina, V.S. Sobolev, A.V. Koroleva, S.A. Pshenichnyuk, N.L. Asfandiarov, A. Modelli, B. Handke, O.V. Borshchev, S.A. Ponomarenko. J. Electron Spectr. Rel. Phenom. 235, 40 (2019).

[15] А.С. Комолов. ЖТФ 76, 13 (2006).

[16] A.S. Komolov, E.F. Lazneva, S.N. Akhremtchik, N.S. Chepilko, A.A. Gavrikov. J. Phys. Chem. C 117, 24, 12633 (2013).

[17] А.С. Комолов, Э.Ф. Лазнева, Н.Б. Герасимова, Ю.А. Панина, А.В. Барамыгин, Г.Д. Зашихин, С.А. Пшеничнюк. ФТТ 58, 367 (2016).

[18] S.A. Pshenichnyuk, A. Modelli, E.F. Lazneva, A.S. Komolov. J. Phys. Chem. A 120, 2667 (2016).

[19] S.A. Pshenichnyuk, A. Modelli, N.L. Asfandiarov, E.F. Lazneva, A.S. Komolov. J. Chem. Phys. 151, 214309 (2019).

[20] С.А. Кукушкин, А.В. Осипов, А.И. Романычев. ФТТ 58, 1398 (2016).

[21] B. Handke, L. Klita, W. Niemiec. Surf. Sci. 666, 70 (2017).

[22] И.А. Аверин, А.А. Карманов, В.А. Мошников, И.А. Пронин, С.Е. Игошина, А.П. Сигаев, Е.И. Теруков. ФТТ 12, 2304 (2015).

[23] I.B. Olenych, O.I. Aksimentyeva, L.S. Monastyrskii, Y.Y. Horbenko, M.V. Partyka, A.P. Luchechko, L.I. Yarytska. Nanoscale Res. Lett. 11, 43 (2016).

[24] L. Grzadziel, M. Krzywiecki, G. Genchev, A. Erbe. Synth. Met. 223, 199 (2017).
[25] F. Moulder, W.F. Stickle, P.E. Sobol, K. Bomben. Handbook of X-ray Photoelectron Spectroscopy. 2nd ed. / Ed. J. Chastain. Eden Prairie: Perkin-Elmer Corporation (Physical Electronics) (1992).

[26] A.S. Komolov, E.F. Lazneva, S.N. Akhremtchik. Appl. Surf. Sci. 256, 2419 (2010).

[27] I. Bartos. Progr. Surf. Sci. 59, 197 (1998).

[28] J. Hwang, A. Wan, A. Kahn. Mater. Sci. Eng. R 64, 1 (2009).

[29] A.S. Komolov, Y.M. Zhukov, E.F. Lazneva, A.N. Aleshin, S.A. Pshenichnuk, N.B. Gerasimova, Yu.A. Panina, G.D. Zashikhin, A.V. Baramygin. Mater. Des. 113, 319 (2017).

[30] A.S. Komolov, S.N. Akhremtchik, E.F. Lazneva. Spectrochim. Acta A 798, 708 (2011).

[13] A.S. Komolov, P.J. Moeller. Colloids and Surfaces A 239, 49 (2004).

[32] A.S. Komolov, P.J. Moeller. Appl. Surf. Sci. 212, 497 (2003).

[33] А.С. Комолов, Э.Ф. Лазнева, Н.Б. Герасимова, В.С. Соболев, Ю.А. Панина, С.А. Пшеничнюк, Н.Л. Асфандиаров, B. Handke. ФTT 62, 1245 (2020).

[34] W. Belza, K. Szajna, M. Kratzer, D. Wrana, K. Cieslik, M. Krawiec, C. Teichert, F. Krok. J. Phys. Chem. C 124, 5681 (2020).

[35] A.L. Shu, W.E. McClain, J. Schwartz, A. Kahn. Organic Electron. 15, 2360 (2014).

[36] S. Braun, W. Salaneck, M. Fahlman. Adv. Mater. 21, 1450 (2009).

[37] А.С. Комолов, Э.Ф. Лазнева, Н.Б. Герасимова, В.С. Соболев, С.А. Пшеничнюк, Н.Л. Асфандиаров, В.А. Крайкин, B. Handke. ФTT 63, 299 (2021).

[38] M. Gruenewald, L.K. Schirra, P. Winget, M. Kozlik, P.F. Ndione, A.K. Sigdel, J.J. Berry, R. Forker, J.-L. Brédas, T. Fritz, O.L.A. Monti. J. Phys. Chem. C 119, 4865 (2015).

Редактор Д.В. Жуманов 